\title{
NEUROPEPTIDE PROCTOLIN IN POSTURAL MOTONEURONS OF THE CRAYFISH ${ }^{1}$
}

\author{
CYNTHIA A. BISHOP, ${ }^{*, 2}$ JEFFREY J. WINE $\ddagger$, AND MICHAEL O'SHEA* \\ ${ }^{*}$ Department of Pharmacological and Physiological Sciences, University of Chicago, Chicago, Illinois 60637 and $\ddagger$ Department of \\ Psychology, Stanford University, Stanford, California 94305
}

Received January 23, 1984; Revised March 9, 1984; Accepted March 12, 1984

\begin{abstract}
The neuropeptide transmitter candidate proctolin (H-Arg-Tyr-Leu-Pro-Thr-OH) was associated with three of the five excitatory motoneurons innervating the tonic flexor muscles of the crayfish abdomen. Proctolin immunohistochemical staining occurred in cell bodies and axons of these three identified neurons. Stained axon terminals were detected across the entire tonic flexor muscle. Bioassay of extracts of the tonic flexor muscles indicated the presence of $370 \mathrm{fmol}$ of proctolin/muscle or $670 \mathrm{fmol} / \mathrm{mg}$ dry weight. Bioactivity was eliminated in muscles in which the tonic flexor motor root was cut 2 months prior to extraction and in muscle extracts pre-incubated with proctolin antiserum. High pressure liquid chromatography purification of tissue extract indicated that all bioactivity in the crude extract was due to authentic proctolin. Our findings suggest that these three cells function as peptidergic motoneurons. A precedent for this is the proctolin-containing postural motoneuron of the cockroach.
\end{abstract}

The pentapeptide proctolin (H-Arg-Tyr-Leu-Pro-Thr-OH) was first found in high concentration in the hindgut or proctodeum of the American cockroach, Periplaneta americana (Brown, 1967; Brown and Starratt, 1975). It was proposed as a candidate neurotransmitter in the hindgut when application of the peptide was shown to produce hindgut contractions similar to those elicited by stimulation of the proctodeal nerve (Brown and Nagai, 1969; Brown, 1975). Immunological studies indicated that the peptide may not be limited to hindgut neurons but may be present in a morphologically diverse population of neurons, widely distributed throughout the central nervous system (Bishop et al., 1981; Bishop and O'Shea, 1982). Among this population, two neurons have been individually identified, isolated, and shown by high pressure liquid chromatography (HPLC) analysis to contain proctolin. These are the lateral white neuron of the cockroach abdominal ganglia, which projects to the heart (O'Shea and Adams, 1981), and the slow depressor motoneuron of the third thoracic ganglion, which innervates muscles in a proximal segment of the cockroach leg (O'Shea and Bishop, 1982).

Recent evidence indicates that proctolin is not confined to

${ }^{1}$ This work was supported by National Institutes of Health Grant NS-06684 (to C. A. B.), National Science Foundation Grants BNS 8112431 (to J. J. W.) and BNS 82-02515 (to M. O.), and a Muscular Dystrophy Association Basic Grant (to J. J. W.). We are grateful to Professor Emil T. Kaiser and William F. DeGrado for the synthesis of an $\mathrm{I}_{2}-\mathrm{Tyr}^{2}$ analogue of proctolin from which $\left[{ }^{3} \mathrm{H}\right.$ |proctolin was prepared by catalytic reduction.

${ }^{2}$ To whom correspondence should be addressed, at Department of Psychology, Stanford University, Jordan Hall, Building 420, Stanford, CA 94305. the cockroach and may be widely distributed in the animal kingdom. Proctolin is bioactive at nanomolar concentrations in a wide variety of insect neuronal and muscular preparations (Piek and Mantel, 1977; May et al., 1979; Miller, 1979; Walker et al., 1980) and in a variety of crustacean nerve and muscle preparations (Schwartz et al., 1980; Benson et al., 1981; Sullivan et al., 1981; Bradbury and Mulloney, 1982; Sylvia and Holman, 1983; Watson et al., 1983). A substance chromatographically indistinguishable from proctolin was detected in the crab pericardial organ (Sullivan, 1979), and proctolin has been shown to cause contractions of the ileum of rats and mice at a threshold of $10^{-8} \mathrm{M}$ (Penzlin et al., 1981).

In this report, we show that proctolin is associated with three individually identified motoneurons in a crustacean. These three neurons are among five excitatory motoneurons which innervate the tonic flexor muscle of the crayfish. This neuromuscular system has been extensively studied for its role in producing the finely graded and sustained flexions responsible for abdominal posture (see Page, 1982, for review). Thus, it may provide a convenient in vivo preparation in which to examine the physiological action and behavioral significance of specific peptide-containing neurons.

Previous work has suggested a functional importance for proctolinergic motoneurons. Studies on the slow depressor motoneuron of the cockroach show that proctolin is released from this neuron along with its conventional transmitter, L-glutamate. Proctolin produces sustained contraction in the synaptically connected depressor muscle, $177 \mathrm{~d}$, independent of the more transient L-glutamate contraction and its paralleling membrane depolarization (Adams and O'Shea, 1983). Thus, proctolin may be responsible for enhancing and prolonging tension, an attribute that could be useful to slow, postural muscles. 


\section{Materials and Methods}

Crayfish, Procambarus clarkii, were obtained from local suppliers and maintained in laboratory tanks. Locusts, Schistocerca nitens, used for the bioassay, were obtained from our laboratory culture. Synthetic proctolin for immunization was obtained from Sigma Chemical Co. Tritiated proctolin $\left(\left[{ }^{3} \mathrm{H}-\mathrm{Tyr}^{2}\right]\right.$ proctolin) was prepared by catalytic reduction (New England Nuclear) of an $\mathrm{I}_{2}-\mathrm{Tyr}^{2}$ analogue of proctolin synthesized by Professor Emil T. Kaiser and William F. DeGrado (Department of Chemistry, University of Chicago).

Immunohistochemical and Lucifer Yellow staining. Female New Zealand White rabbits were immunized subcutaneously with glutaraldehyde conjugates of synthetic proctolin (Sigma) to bovine serum albumin, emulsified with Freund's adjuvant. Serum titer, sensitivity, and specificity were checked by radioimmunoassay using proctolin to displace serum-bound radioiodinated proctolin. Details of the methods and characteristics of the sera raised have been described elsewhere (Bishop et al., 1981). One of the antisera raised in this manner (no. 9 of Bishop et al., 1981) was used to visualize proctolin-like antigens in unsectioned whole ganglia, peripheral nerves, and muscles by the peroxidase-antiperoxidase technique (Sternberger, 1979). Details of these methods are similar to those used to stain proctolin-like immunoreactive neurons in the cockroach and are described in detail elsewhere (Bishop and O'Shea, 1982). Our present procedurc differed from that used for cockroach in that $0.1 \mathrm{M}$ sodium phosphate $(\mathrm{pH} 7.4)$ replaced the $\mathrm{NaCl} /$ Tris buffer $(0.05 \mathrm{M}$ Tris containing $0.9 \% \mathrm{NaCl}, \mathrm{pH}$ 7.6). Furthermore, all concentrations of the detergent Triton $\mathrm{X}-100$ were increased 10 -fold. The phosphate buffer was found to produce a better signal to noise ratio by lowering the background coloration. Increased Triton X-100 enhanced antisera penetrability. Immunoreacted peripheral nerves were occasionally embedded in Durcupan plastic (Fluka) and sectioned $(12 \mu \mathrm{m})$. All proctolin-like immunoreactivity in the crayfish was eliminated when the antiserum was preincubated with $0.5 \mathrm{mg} / \mathrm{ml}$ of synthetic proctolin or substituted with pre-proctolin-immunized rabbit serum. Three to five gelatin pellets containing $1 \%$ colchicine (Pitman, 1975) were sometimes placed in the abdomen of the crayfish 4 to 7 days prior to the dissection. This procedure enhanced cell body staining in the abdominal ganglia.

For combined Lucifer Yellow and immunohistochemical staining, cell bodies of the tonic flexor system were first backfilled with Lucifer Yellow. To backfill, abdominal nerve cords were removed and placed in a Sylgard-coated dish with the freshly cut end of the tonic flexor motor root isolated in a Vaseline pool of a $3 \%$ solution of Lucifer Yellow in distilled water. The rest of the nerve cord was kept submerged in van Harreveld's physiological solution (van Harreveld, 1936). The preparation was kept at $4^{\circ} \mathrm{C}$ for $6 \mathrm{hr}$, then submerged in fixative. The fluorescing cell bodies filled with Lucifer Yellow were photographed while the uncleared tissue remained in fixative. The nerve cords were processed for immunoreactivity as described above, cleared, then examined again microscopically for residual Lucifer Yellow fluorescence and immunoreactivity.

Muscle extraction. Tonic flexor muscles were exposed from the ventral side of the crayfish. Muscles from segments 2 through 4 were eased away from their attachment sites, removed, and collected on dry ice. Tissue was homogenized in $1 \mathrm{ml}$ of methanol/water/acetic acid (90:9:1) and centrifuged. The supernatant was transferred to another tube and evaporated at $70^{\circ} \mathrm{C}$. The dried samples were redissolved in either locust isotonic physiological saline for bioassay or double-distilled water and run through a small $\mathrm{C}_{18}$-containing SepPak (Waters Associates) cartridge (Adams and O'Shea, 1983).

Bioassay. An extremely sensitive and reliable proctolin bioassay was used to measure the amount of proctolin present in the muscles. The bioassay makes use of a myogenic oscillation in a small, specialized bundle of muscle fibers within the main extensor muscle of the locust hindleg (O'Shea and Adams, 1980; O'Shea and Bishop, 1982). Proctolin produces a pattern of increased frequency and basal tone in this muscle, referred to as proctolin-like bioactivity (PLB) (O'Shea and Adams, 1980). Threshold for this response is in the range of 10 to $100 \mathrm{pmol}$. A methathoracic leg of immature adult female specimens of the locust $S$. nitens was removed and dissected to expose the myogenic bundle in the proximal region of the femur. The exposed bundle was bathed in $10 \mu \mathrm{l}$ of isotonic physiological locust saline (O'Shea and Adams, 1980), and $1-\mu l$ aliquots of test solutions (standards and tissue extracts) were applied to the muscle. The small movements of the tibia produced by the myogenic fibers were monitored with a photoelectric movement detector. After each $1-\mu \mathrm{l}$ sample application and response, the muscle was washed with about $5 \mathrm{ml}$ of isotonic saline prior to the next application. For quantification, the peak frequency of contractions attained in a response was compared on a standard curve to a similar response to proctolin. Proctolin-like bioactivity is, therefore, expressed equivalent to a given mass of proctolin. One preparation can be used to test as many as $1001-\mu$ l samples.

HPLC. Samples eluted from the $\mathrm{C}_{18}$ SepPak cartridge with $80 \%$ methanol were dried in a $70^{\circ} \mathrm{C}$ oven and then redissolved in either isotonic physiological saline for bioassay or chromatography solvents for HPLC purification. Extracts were chromatographed on a $10-\mu \mathrm{m}$ Bondapak $\mathrm{C}_{18}$ reverse phase column (Alltech). A volatile liquid phase (50 mM ammonium acetate, $15 \%$ acetonitrile, $\mathrm{pH} 4.5$ ) was pumped at $1.5 \mathrm{ml} / \mathrm{min}, 1800 \mathrm{psi}$, and $0.3-\mathrm{min}$ fractions were collected. Elution time of proctolin in this system was determined by chromatography of tritium-labeled proctolin $\left(\left[{ }^{3} \mathrm{H}-\mathrm{Tyr}^{2}\right]\right.$ proctolin). Chromatographed fractions were bioassayed after evaporating the liquid phase under reduced pressure and redissolving each dried fraction in isotonic physiological saline.

\section{Results}

In crayfish, abdominal postural muscles that produce graded and sustained flexions are located just under the soft ventral exoskeleton in each bilateral half of the abdomen's first five segments (Fig. 1). Each tonic flexor muscle consists of a thin sheet of approximately 40 muscle fibers and is innervated by its own purely motor root which contains one inhibitory and five excitatory axons, labeled $\mathrm{f} 1 \mathrm{to}$ f 6 according to the increasing size of their axons (Fig. 9B). The inhibitory axon is the second largest, f5 (Kennedy and Takeda, 1965; Sokolove and Tatton, 1975).

Processing with a proctolin antiserum revealed prominent immunohistochemical staining in axons in the tonic flexor motor roots of all five segments (Fig. 6). Staining was prevented by pre-incubating the antiserum with authentic proctolin. These results suggest that proctolin is present in the motoneurons of the tonic flexor muscles. To explore this possibility further, we checked proctolin-like immunoreactivity (PLI) on the tonic flexor muscles, PLB in muscle extracts before and after HPLC purification, and PLB after treatment with the proctolin antiserum. We also examined PLB in extracts of muscles with severed tonic flexor motor roots. This operation promoted depletion of the peptide from motoneuron terminals by eliminating their cell bodies, where the peptide is presumably synthesized.

Proctolin immunoreactivity on the tonic flexor muscles. Staining in the tonic flexor motor root was traced to the tonic flexor muscle where immunoreactive axons branched (Fig. 2A). Branches were followed to smaller processes which terminated on muscles fibers. Darkly staining varicosities and blebs were distributed along these fine processes (Fig. $2 B$ ). Immunoreactive terminals and blebs were closely associated with the individual muscle fibers (Fig. $2 \mathrm{C}$ ). Immunoreactive terminals were located on every muscle fiber of the tonic flexor muscle. All staining was eliminated by cutting the tonic motor nerve root 2 months prior to immunohistochemical processing.

Proctolin bioactivity in the tonic flexor muscles. We bioassayed extracts of isolated tonic flexor muscles and compared the results to those obtained with authentic proctolin. Figure $3 A$ shows the response of the myogenic oscillator bioassay to the crude muscle extract. There is a close qualitative similarity between this response and that of authentic proctolin shown in Figure $3 E$. Both show an increase in basal muscle tone and the frequency of the myogenic rhythm.

Bioactivity was quantified by measuring the increase in frequency of the myogenic oscillator produced by extracts and proctolin standards. In the example shown in Figure $3 A$, a $1-\mu 1$ aliquot of the extract produces a response intermediate between the same amounts of 2.5 and $5 \mathrm{~nm}$ proctolin. We have calculated from similar results that each tonic flexor muscle contains 

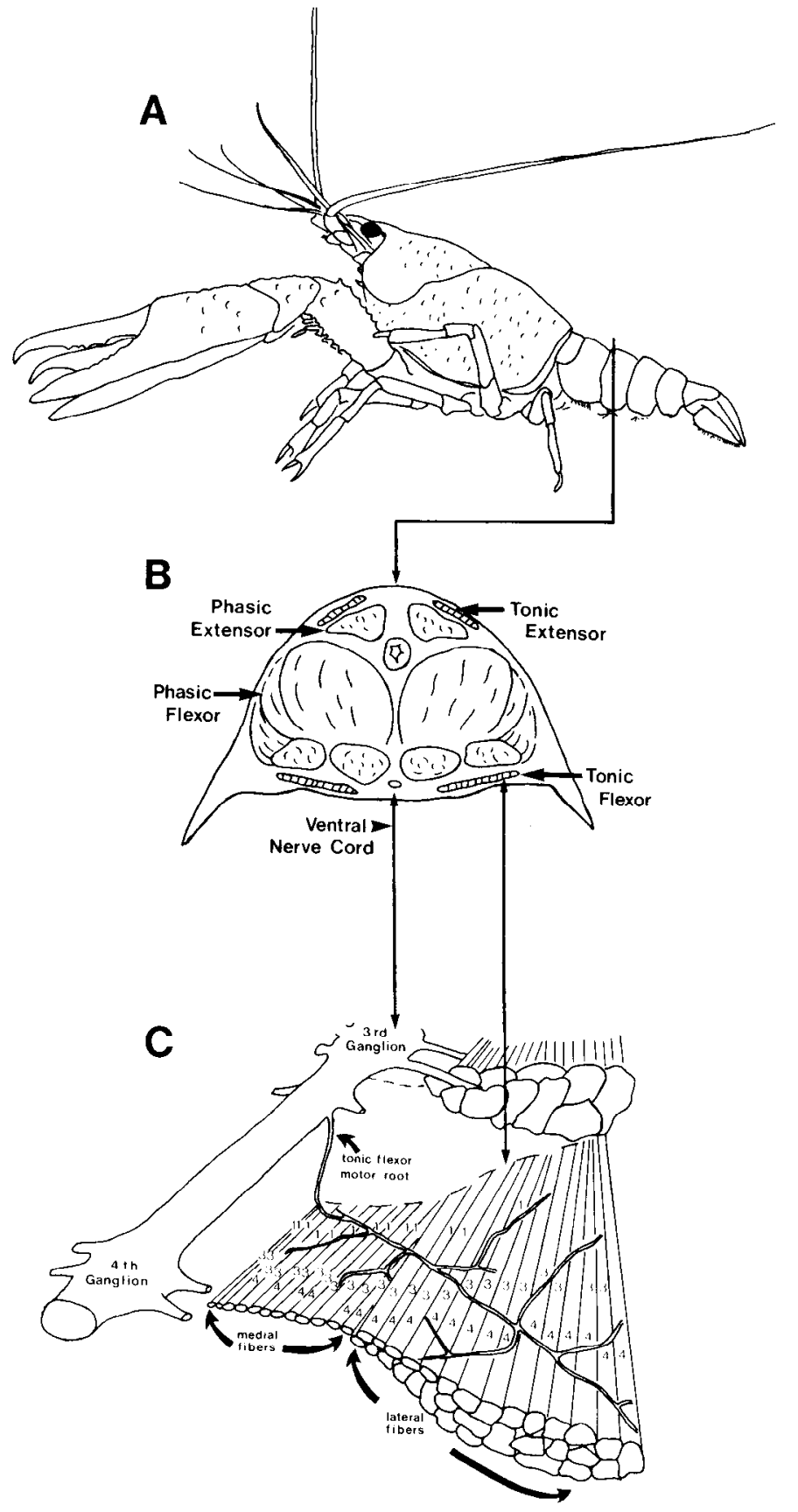

Figure 1. Tonic muscles controlling the graded changes in abdominal posture of the crayfish are completely separated from the massive phasic muscles used in swimming. A pair of the tonic flexors occurs as sheets just under the soft, clear ventral surface of the exoskeleton of the first five abdominal segments (Kennedy and 'I'akeda, 1965). $A$, Experimental animal, the crayfish, Procambarus clarkii. $B$, Crosssection through the abdomen indicating the relative positions of the tonic flexor muscles to the nerve cord, exoskeleton, and other major muscle masses. $C$, Dorsal view of nerve cord and tonic flexor muscle from the third segment. Numbers on muscle fibers indicate synaptic connections between motoneurons $\mathrm{f} 1, \mathrm{f} 3$, and $\mathrm{f} 4$ and individual muscle fibers. ( $A$ and $B$, modified from Wine et al., 1974; $C$, modified from Clement et al., 1983.)

bioactivity equivalent to $370 \mathrm{fmol}$ of proctolin, or $673 \mathrm{fmol}$ of proctolin/mg dry weight of tonic flexor muscle. These values are considerably higher than those found for the cockroach depressor muscle, $177 \mathrm{~d}$, which had PLB equivalent to $37 \mathrm{fmol}$ of proctolin/muscle, or $140 \mathrm{fmol} / \mathrm{mg}$ dry weight (Adams and O'Shea, 1983; M. E. Adams, personal communication). Normalizing for dry weight, the crayfish muscle contains 4.8 times the amount of PLB found in the cockroach muscle.

PLB extracted from the nerve/muscle preparation is associated with the tonic flexor motor terminals rather than with the muscle itself. Figure $3 B$ shows the bioassay response of an extract from muscles contralateral to those used for the extract of Figure $3 A$. However, these muscles produced virtually no proctolin response in the bioassay because their tonic flexor motor roots were cut 2 months prior to extraction. We ascribe this effect to depletion of proctolin from the motor innervation of the muscle.

Bioactivity to the muscle extract used in $A$ of Figure 3 was eliminated by pre-incubating the extract with our proctolin rabbit antiserum (Fig. $3 D$ ) but not with pre-immunized (normal) rabbit serum (Fig. $3 C$ ). In these experiments, the serum or antiserum was mixed 1:15 with the muscle extract. This further demonstrates the association between the PLB of the muscle and the PLI detected in the motoneurons.

We verified that the PLB in the crude muscle extract is due to authentic proctolin by HPLC purifying muscle extracts, bioassaying the eluted fractions, and comparing the results to a parallel fractionation of $\left[{ }^{3} \mathrm{H}\right]$ proctolin. Only one peak of bioactivity was detected in the eluted fractions (bars in Fig. 4), and this peak cannot be separated from that produced by the $\left[{ }^{3} \mathrm{H}\right]$ proctolin (circles in Fig. 4). After HPLC purification, 350 fmol/muscle of PLB were recovered. The closeness of this number to that measured for the crude, unfractionated extract indicates that all PLB measured in the crude extract of the tonic flexor muscle was due to authentic proctolin in the motor innervation.

Taken together, these results indicate that the proctolin located in the tonic flexor muscle is associated with the terminals of the tonic flexor motoneurons. Which of the six motoneurons contain the peptide? The larger quantity of proctolin in the crayfish muscle compared to the cockroach and a distribution of immunoreactive terminals wider than the terminal field of any individual neuron (Velez and Wyman, 1978a, b) suggest that proctolin is present in more than one motoneuron. In the next section, we will examine the proctolin immunoreactivity of the six tonic flexor motoneurons and exploit the special features of the tonic flexor motor pool to identify which of these cells contains proctolin immunoreactivity. These features include: (1) the size and location of each soma are distinctive, $(2)$ the axons runs alone in a purely motor root, and (3) the axon diameters are distinctively different from one another and are correlated with soma diameters (Kennedy and Takeda, 1965; Wine et al., 1974; Sokolove and Tatton, 1975).

Proctolin immunoreactivity in three tonic flexor motoneurons. Figure 5 shows three ganglionic preparations after immunohistochemical processing for proctolin. Three pairs of somata are indicated. The locations of these somata are consistent with the identified tonic flexor motoneurons $\mathrm{f} 1$, $\mathrm{f} 3$, and $\mathrm{f} 4$, found by cobalt backfills by Wine et al. (1974; refer to summary diagram in Fig. 9A). The somata showing PLI are also equivalent in size to $\mathrm{f} 1, \mathrm{f} 3$, and $\mathrm{f} 4$. Those described by backfill technique were $12 \mu \mathrm{m}$ (f1), $31 \mu \mathrm{m}$ (f3), and $38 \mu \mathrm{m}$ (f4); the corresponding immunoreactive cell bodies averaged $11 \mu \mathrm{m}, 32 \mu \mathrm{m}$, and $43 \mu \mathrm{m}$, respectively. Although over five other pairs of proctolin immunoreactive somata were detected in each of the first five abdominal ganglia (C. A. Bishop, J. J. Wine, and M. O'Shea, manuscript in preparation), in over 30 colchicine-treated preparations of the nerve cord, no staining was seen in somata corresponding in position and size to motoneurons $\mathrm{f} 2$, $\mathrm{f} 5$, or $\mathrm{f} 6$

When we examined immunoreactivity in whole mounts of the tonic flexor molor root, we also detected a maximum of three staining axons. (More than 20 nerve cords not treated 

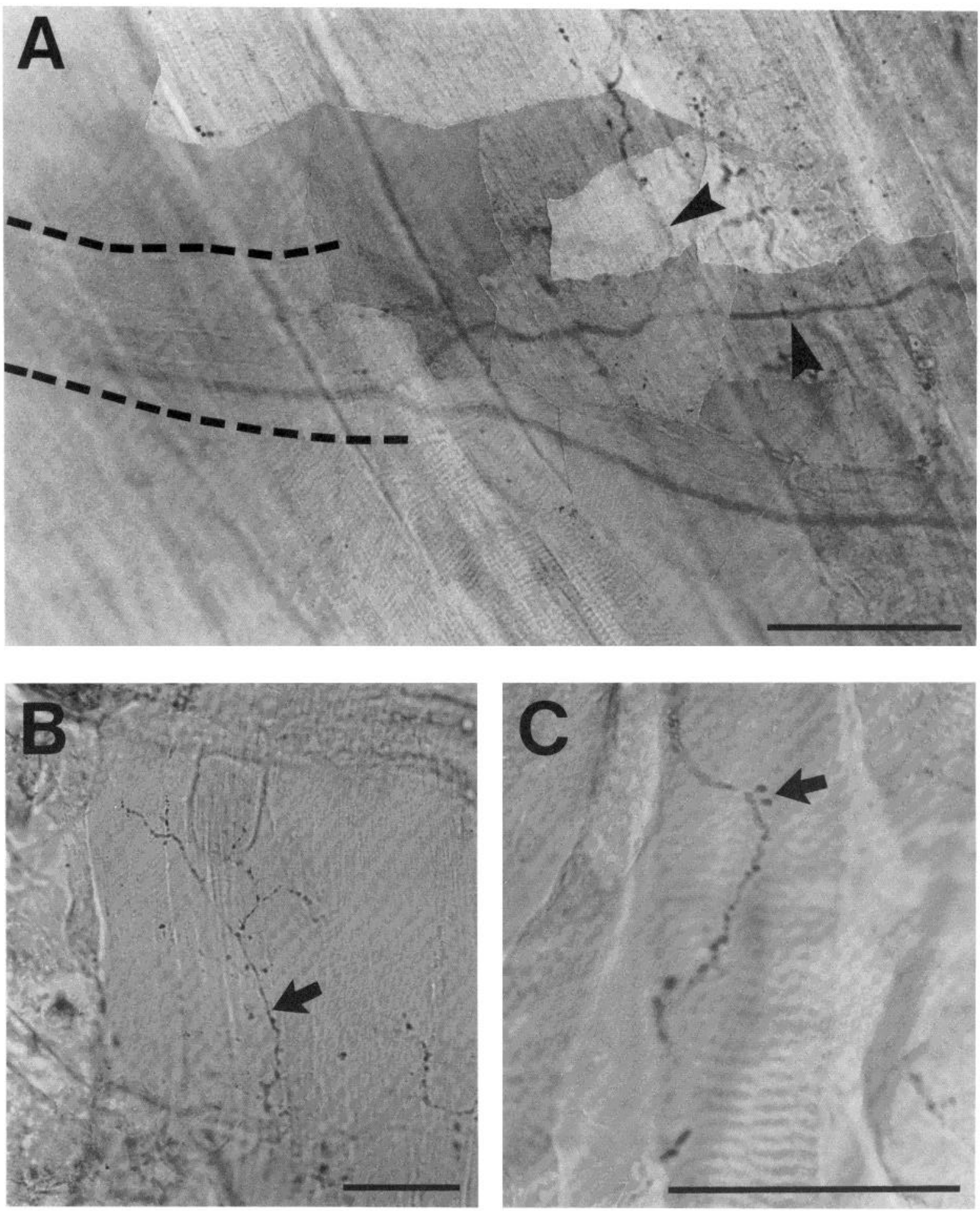

Figure 2. Proctolin-like immunoreactivity on the tonic flexor muscles. A, Composite of an immunoreactive axon from the tonic flexor root branching onto the muscle. Immunoreactive branches are indicated with arrow heads. Large nonimmunoreactive axons can be detected in the outlined tonic flexor root. $B$, Darkly staining varicosities and blebs are distributed along the terminals of an immunoreactive axon (arrow). $C$, Higher magnification of an immunoreactive axon terminal showing its close association with a tonic flexor muscle fiber. The arrow indicates two immunoreactive varicosities. Scale bars: $100 \mu \mathrm{m}$.

with colchicine and 30 that were treated were examined.) Two were medium-sized (approximately 8 and $10 \mu \mathrm{m}$ ), and one was a much smaller axon of $2 \mu \mathrm{m}$ (Fig. 6). We cross-sectioned ten roots to compare the diameters of stained and non-stained axons (Fig. 7). The two largest axons (average diameters of 15 and $20 \mu \mathrm{m}$ ) and one small axon of $4 \mu \mathrm{m}$ never stained with the antibody. Immunoreactivity in the root was confined to motoneuron axons and never associated with the blood vessel or other structures of the tonic flexor motor root. Thus, proctolin immunoreactivity is associated only with the two medium-sized 
A control

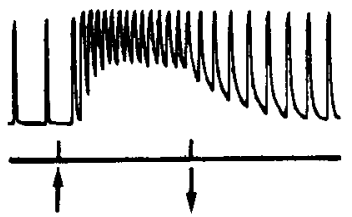

B denervated

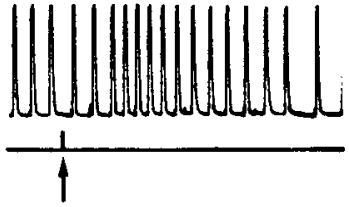

C control + serum

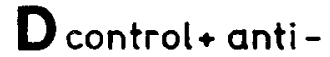
serum
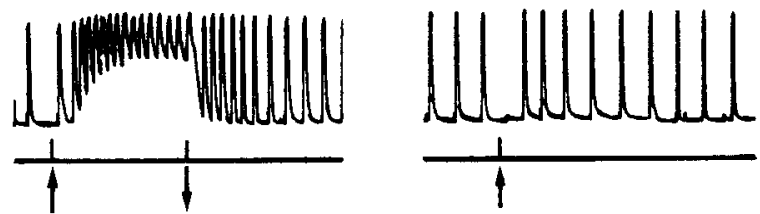

$\mathbf{E}_{\text {proctolin standards }}$

$2 \min$

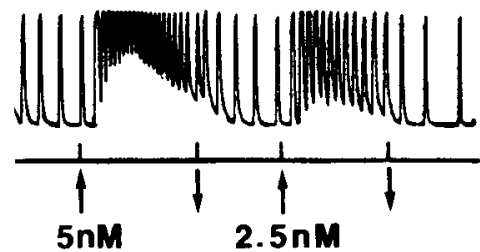

Figure 3. Bioassay evidence for proctolin in motoneurons. Effects of application of $1-\mu \mathrm{l}$ aliquots of tonic flexor muscle extract or authentic proctolin standard on the myogenic contractions of the locust extensor muscle are monitored using a photoelectric movement detector. The upward arrows indicate application of extract or standard. The downward arrows indicate washes with physiological saline. $A$, Response to application of tonic flexor muscle extract. The slow tonic contracture and increase in frequency of the rhythmic contractions are qualitatively similar to those seen when authentic proctolin is applied (compare to $E)$. $B$, Response to the bilaterally symmetric tonic flexor muscles whose tonic flexor roots had been severed 2 months prior to extraction. $C$, Effect of tonic flexor muscle extract incubated with normal rabbit serum. $D$, Effect of the same muscle extract as used in $C$, following incubation with anti-proctolin rabbit serum. $E$, Effect of two proctolin standards. Note that the larger concentration produces a greater increase in frequency and a larger tonic contracture.

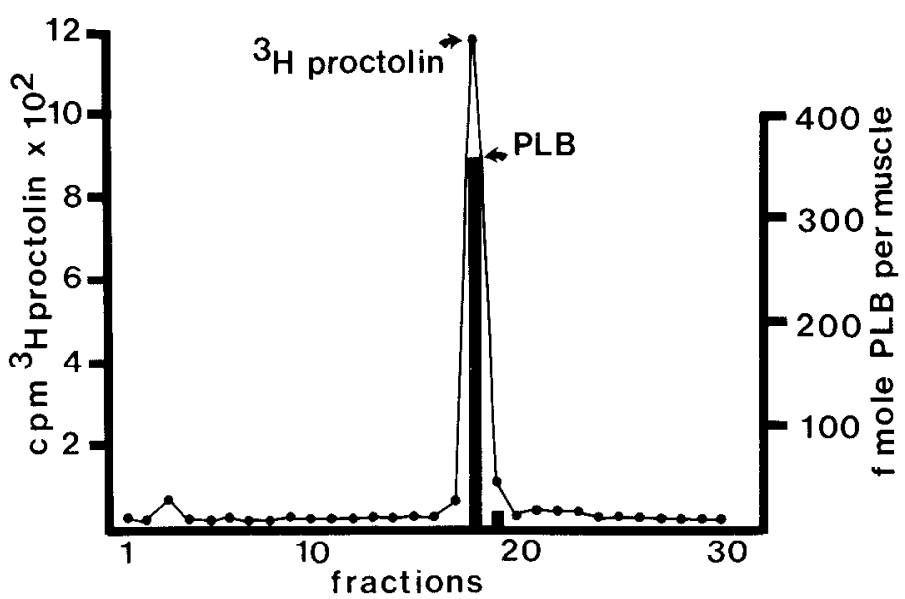

Figure 4. Co-elution of $\left[{ }^{3} \mathrm{H}\right]$ proctolin (circles) and PLB (solid bars) in reverse HPLC. axons and the smallest axon, or $\mathrm{f} 4, \mathrm{f} 3$, and $\mathrm{f} 1$. This result also correlates with the staining seen in the somata of the motoneurons.

Unfortunately, the caprice of the immunohistochemical staining made it impossible to trace stained axons to the stained somata. However, we were able to substantiate that one immunoreactive soma was the tonic flexor motoneuron, f3, by double labeling with Lucifer Yellow and the proctolin antiserum. We identified the soma of $\mathrm{f} 3$ by first backfilling it from the axon root with Lucifer Yellow and subsequently staining with the proctolin antiserum in 20 preparations. An example is shown in Figure 8. Although Lucifer Yellow fluorescence in $\mathrm{f} 3$ is quenched after immunohistochemical processing and there is some tissue shrinkage, it was still possible to identify $\mathrm{f} 3$ by its shape and position in the ganglion and its position relative to the residual fluorescence in other flexor motoneurons.

It should also be noted that the synaptic distribution of $\mathrm{f} 1$, $\mathrm{f} 3$, and $\mathrm{f} 4$ correlates with the distribution of staining found on the muscle. Figure $1 C$ illustrates the synaptic distribution of $\mathrm{f} 1, \mathrm{f} 3$, and $\mathrm{f} 4$ (Clement et al., 1983) which is sufficient to account for the detected distribution of axon terminals over the entire muscle.

In summary, our results suggest that the tonic flexor motor pool may be subdivided into two populations, one of which contains proctolin (Fig. 9).

\section{Discussion}

We began this study knowing that proctolin is present in a skeletal motoneuron in the cockroach, where it exists as a neuromuscular co-transmitter and appears to enhance and prolong tension in a slow, postural muscle of the leg (O'Shea and Bishop, 1982; Adams and O'Shea, 1983). We are interested in whether proctolin is used for analogous functions in other species.

We have now shown that proctolin also exists in a specific subpopulation of crustacean skeletal motoneurons, whose targets are likewise involved in postural control. These motoneurons innervate axial abdominal muscles which are not homologous with the cockroach appendage muscles. However, there are several functional similarities between the proctolinergic motoneurons of the two animals. For example, in both animals proctolin presumably coexists with another transmitter and may not itself cause EPSPs in the muscle fibers. For the crayfish, this is inferred by the fact that crayfish motoneurons isolated from their cell bodies continued to generate normal EPSPs for many weeks, long after all proctolin should be depleted (Hoy et al., 1967; Bittner, 1977). For both animals, the classical excitatory neurotransmitter of motoneurons is thought to be L-glutamate (Takeuchi and Takeuchi, 1961; Kravitz et al., 1970; Evoy and Beranek, 1972; Usherwood, 1980).

It is also possible that proctolin generates sustained tension in the crayfish muscles, uncorrelated with membrane depolarization, similar to that generated in the cockroach muscle. Such sustained tension changes in the tonic flexor muscles have already been reported (Evoy et al., 1967; Gillary and Kennedy, 1969). A proctolin function that is independent of membrane potential in this crayfish neuromuscular system, combined with our current notion that there are two populations of neurons in this system which are either proctolinergic or nonproctolinergic, may, in turn, shed light on the longstanding puzzle of polyinnervation of this muscle by neurons that appeared to be rather homogenous in their electrical effects. In this regard, it is interesting to note that no one excitatory motoneuron generally synapses on all tonic flexor muscle fibers. Together, however, members of each of the two motor pools contact all muscle fibers. It will be interesting to determine whether the linergic pool is differentially recruited by control motor programs. 

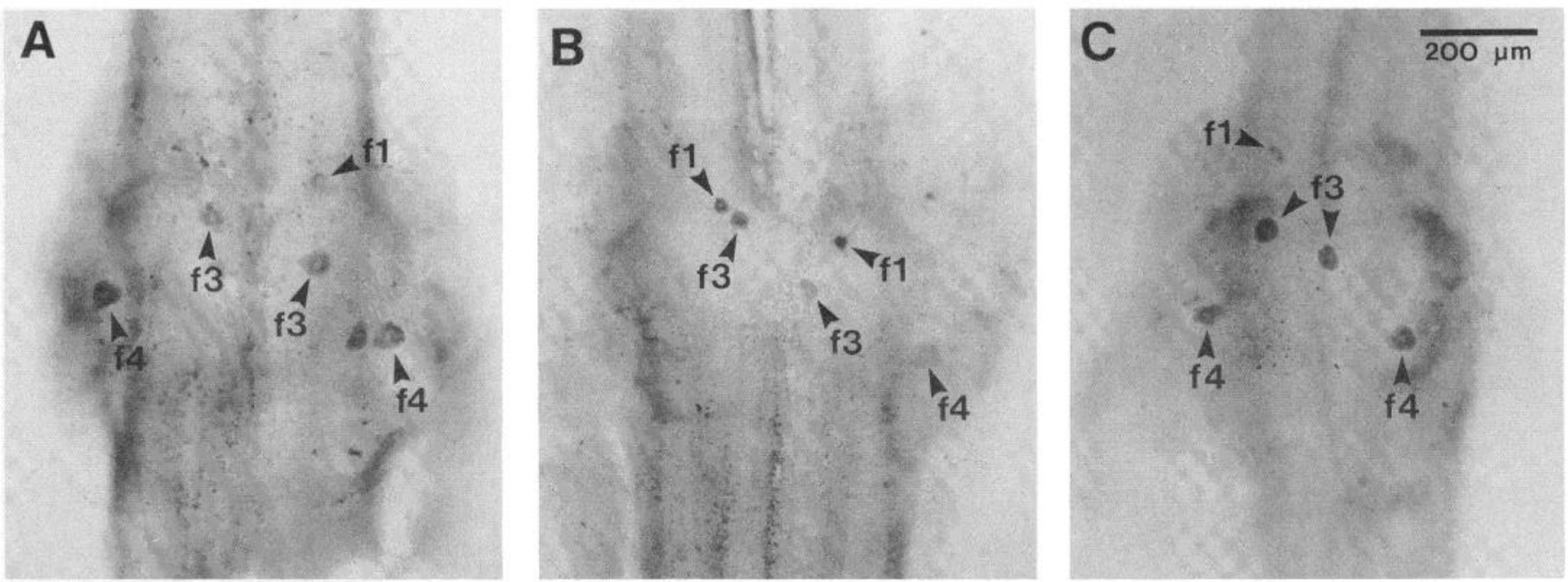

Figure 5. Whole mount preparations of abdominal ganglia demonstrating immunoreactive somata appropriate in size and position for tonic flexor motoneurons $\mathrm{f} 1, \mathrm{f} 3$, and $\mathrm{f} 4$. These ganglia have been treated with colchicine to intensify cell body staining. Intense staining in somata f1 and $\mathrm{f} 4$ appears particularly dependent on colchicine, and the variability seen in these three preparations is believed to be due to variable colchicine penetration. $A$ and $B$, Two second abdominal ganglia. $C$, Third abdominal ganglion.

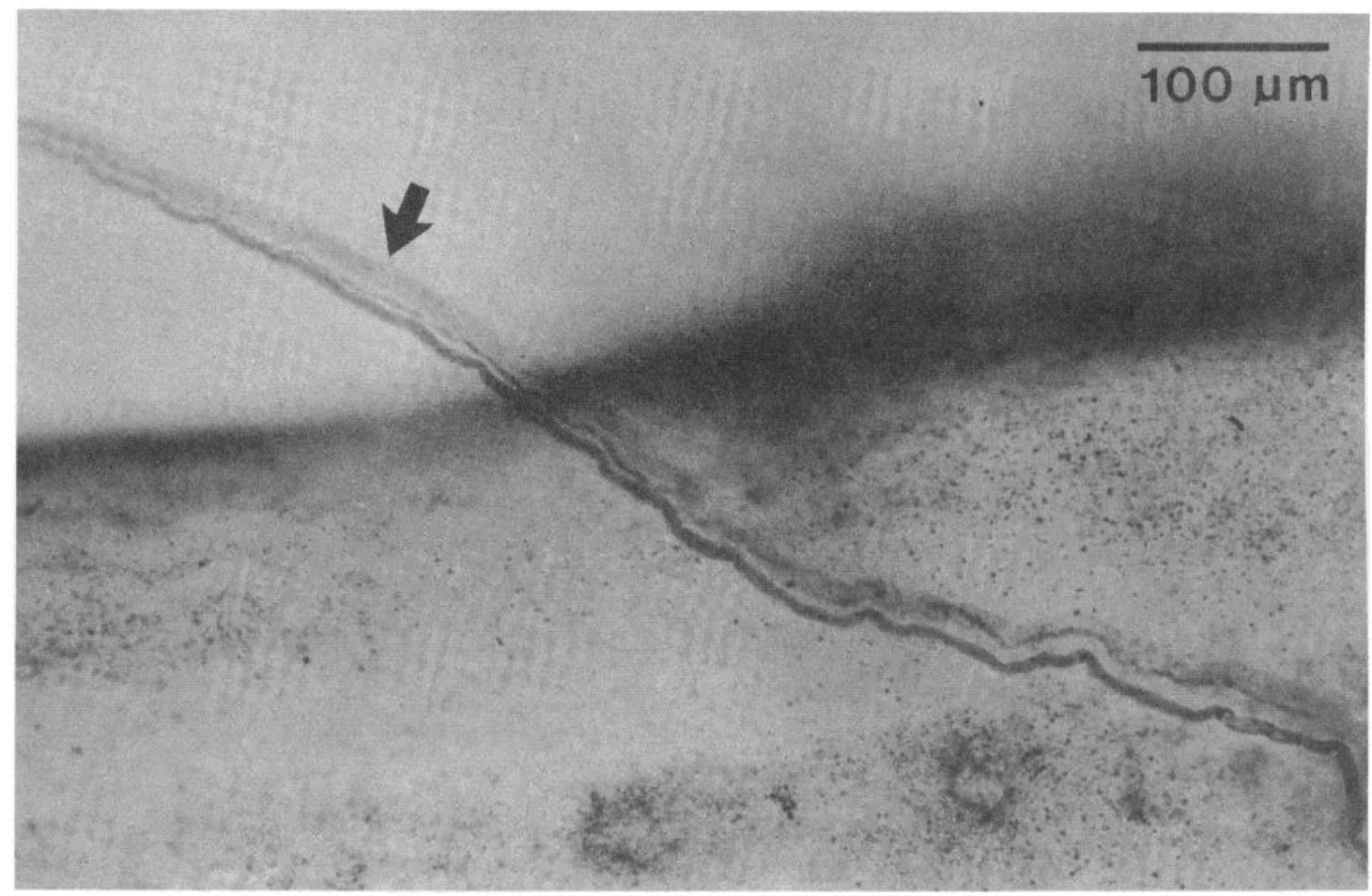

Figure 6. Tonic flexor motor root preparations demonstrating PLI in three axons (arrow). The largest axon is lightly stained in this preparation.

Our division of the tonic flexor motoneurons into proctolinergic and nonproctolinergic pools does not exclude the possibility that the nonproctolin pool may also contain peptide transmitters. Indeed, it is possible that peptides other than proctolin, such as those recently purified by O'Shea et al. (1984), may also be involved in neuromuscular transmission in arthropods. It seems likely that invertebrate neuromuscular systems will provide a variety of preparations for function analysis of a variety of peptide transmitters.

The results reported here, combined with our studies in cockroach (O'Shea and Bishop, 1982; Adams and O'Shea, 1983), show that the motoneuron pool is heterogeneous in transmitter content and may, like other neurons, contain a complex complement of transmitters and co-transmitters. This concept has recently been suggested for vertebrate motoneurons, where synthesizing enzymes for three neurotransmitters, dopamine, $\gamma$-aminobutyric acid (GABA), and taurine, were found coexisting in motoneurons with acetylcholine (Chan-Palay et al., 1982). 

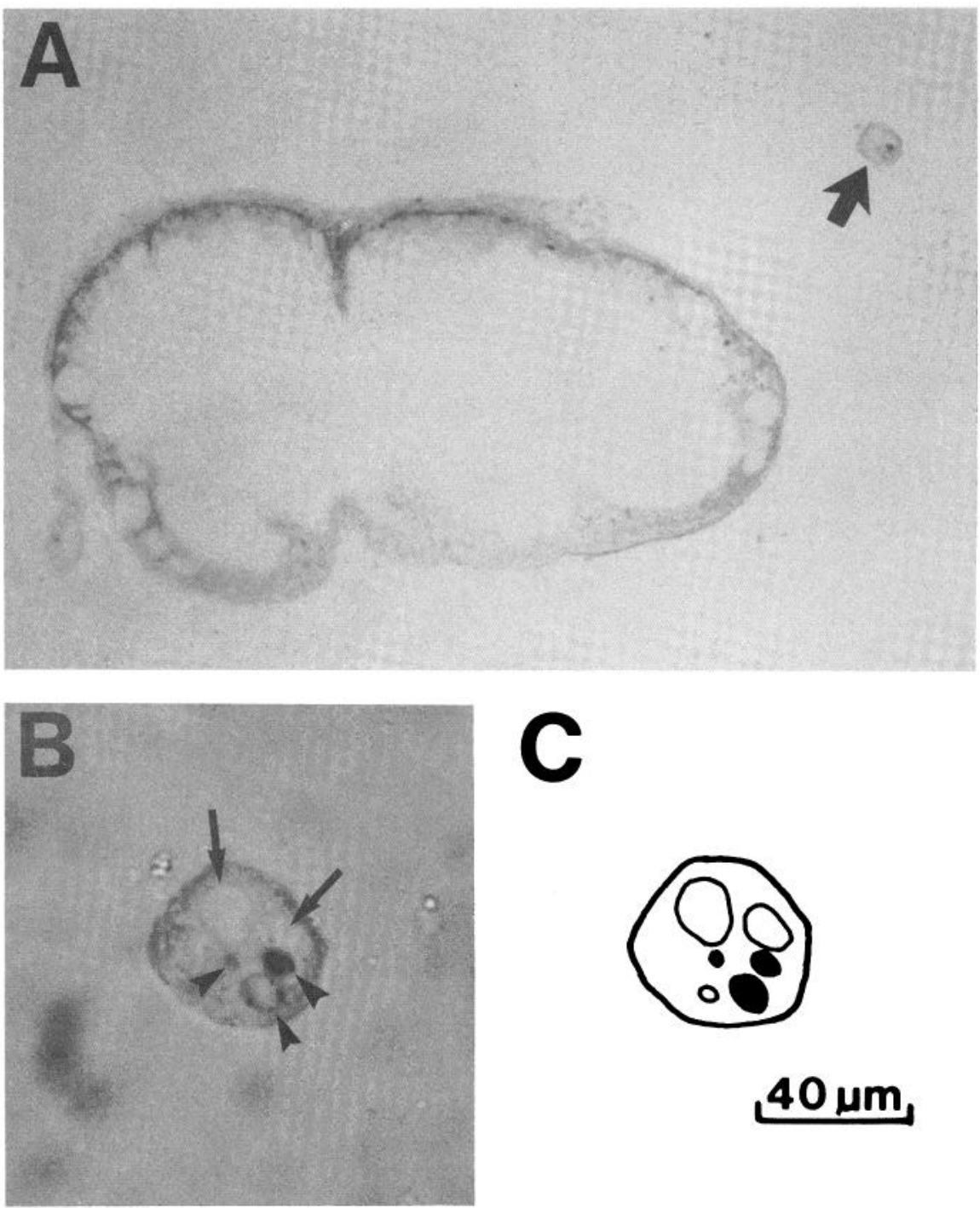

\section{$40 \mu \mathrm{m}$}

Figure 7. A, Cross-section through connective and tonic flexor motor root in which three axons are stained. The arrow indicates the tonic flexor motor root. $B$, Higher magnification of the tonic flexor motor root. Immunoreactive axons are indicated by arrowheads. Immunoreactivity in the largest staining axon is located around the periphery of the axon only in this preparation. Two large nonstaining axon profiles are indicated by the arrows. The smaller of the two is just out of focus. An unstained small axon profile is also present in this preparation but is undetectable in the plane of focus of this photograph. $C$, Camera lucida drawing of the six motoneuron axon profiles from this cross-section. Blackened axons indicate proctolin immunoreactivity. 

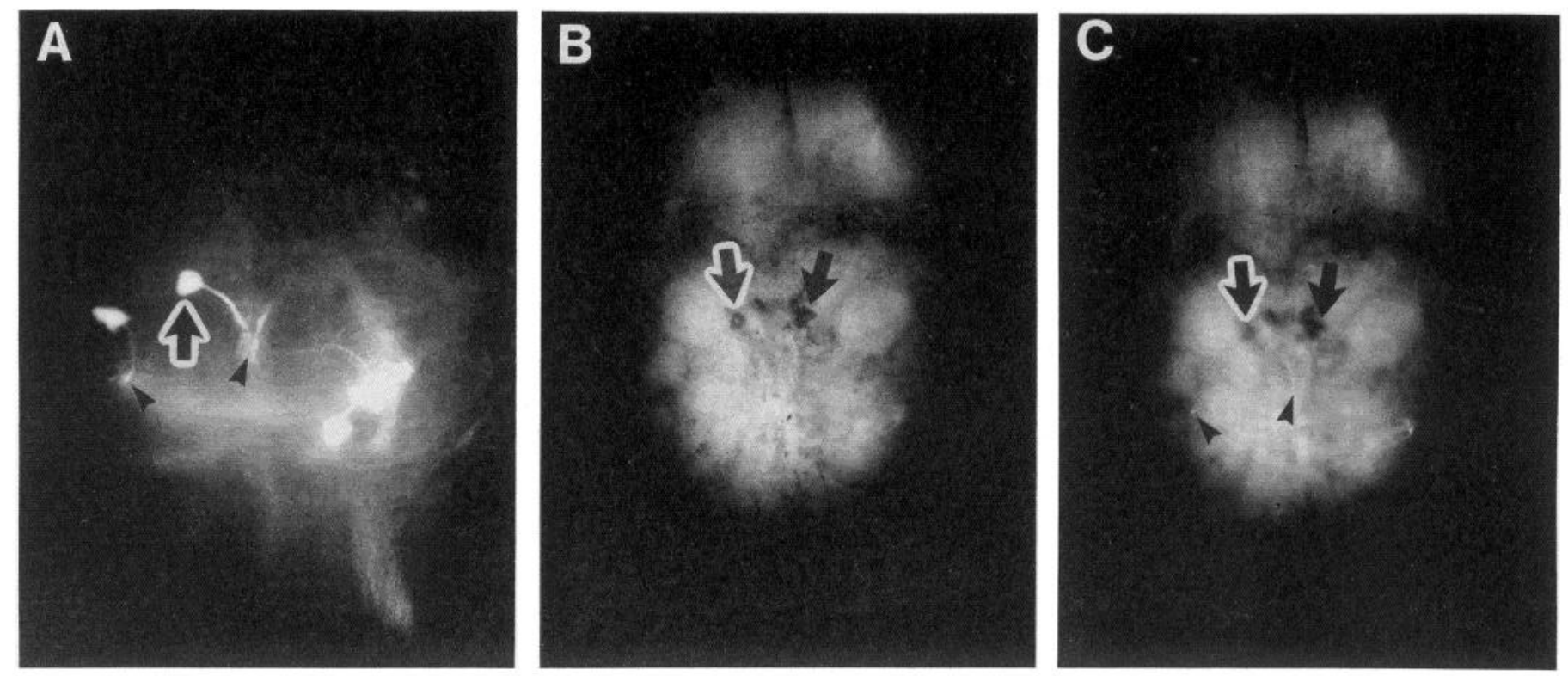

Figure 8. Second abdominal ganglion in which tonic flexor motoneurons were backfilled with Lucifer Yellow from one root, subsequently stained with the proctolin antibody using the PAP procedure, and viewed with UV illumination. $A$, Preparation prior to antibody processing. The white outlined arrow indicates the backfilled f 3 soma. $B$ and $C$, Two focal planes of the preparation after antibody processing. White outlined arrows indicate a comparable cell body to $\mathrm{f} 3$ that stains with the antibody. Black arrows indicate the immunoreactive homologue. $C$ shows residual fluorescence in the neurite of $\mathrm{f} 3$ and in parts of other tonic flexor motoneurons. (Small arrowheads in $A$ and $C$ show points of comparison.) Although Lucifer Yellow fluorescence is quenched in the f3 soma after antibody staining, we believe that the dye-filled cell is stained with the antibody because it is similar in shape and position in the ganglion and has a maintained position relative to the residual fluorescence. (Motoneurons f1 and f4 did not stain in these backfilled preparations because colchicine was not used.)

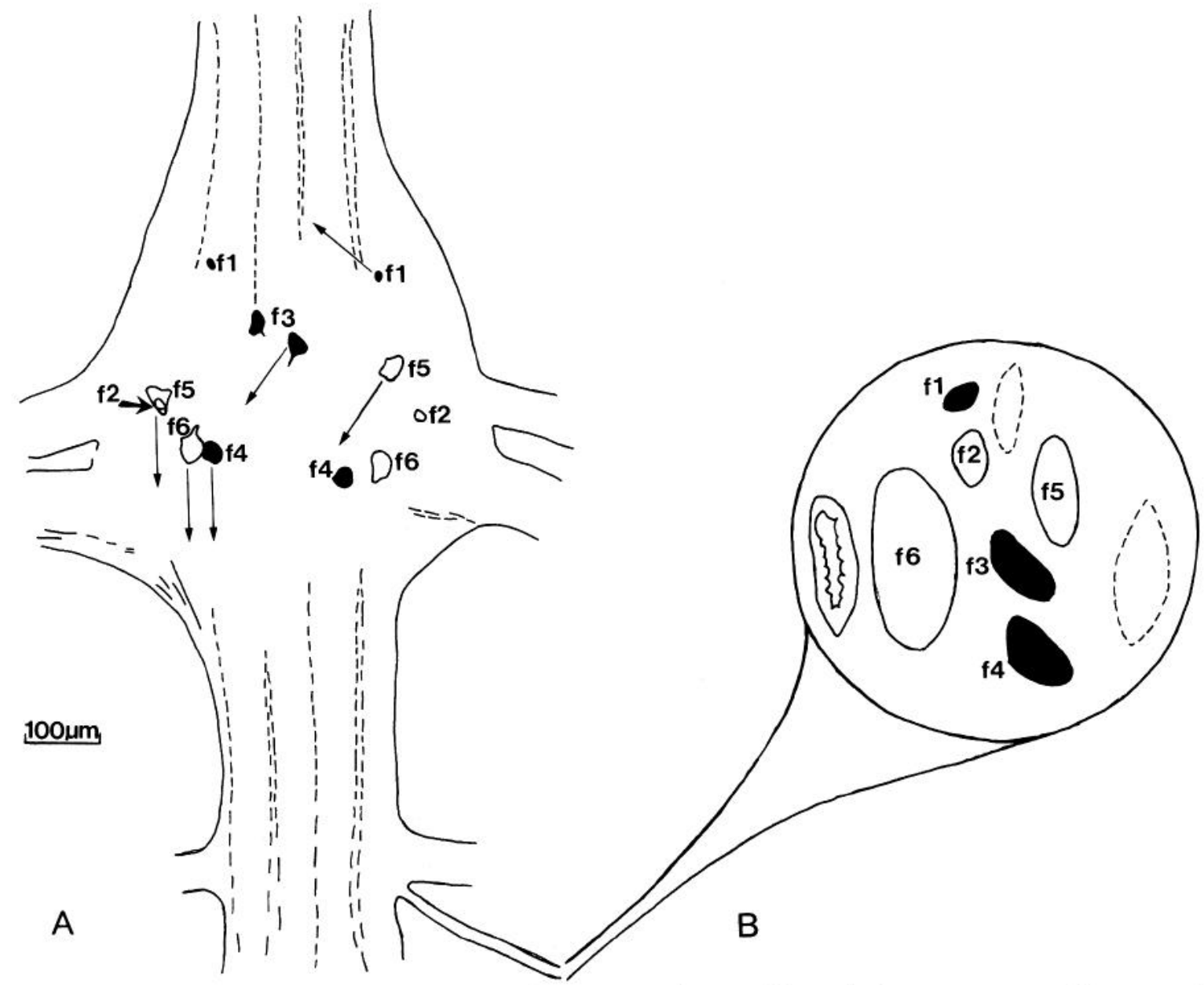

Figure 9. Summary of proctolin immunoreactivity (blackened) in somata and axons of the tonic flexor motoneurons. The arrows in $A$ indicate the innervated muscle. In $B$, broken lines indicate clusters of many small tubular structures of unknown function present in the proximal part of the tonic flexor motor root. The other unlabeled structure represents a blood vessel. ( $A$, modified from Wine et al., 1974; $B$, modified from Sokolove and Tatton, 1975.) 


\section{References}

Adams, M. E., and M. O'Shea (1983) Peptide co-transmitter at a neuromuscular junction. Science 221: 286-289.

Benson, J. A., R. E. Sullivan, W. H. Watson, and G. J. Augustine, Jr. (1981) The pentapeptide proctolin acts directly on Limulus cardiac muscle to increase the amplitude of contraction. Brain Res. 213: 449454.

Bishop, C. A., and M. O'Shea (1982) Neuropeptide proctolin (H-ArgTyr-Leu-Pro-Thr-OH): Immunocytochemical mapping of neurons in the central nervous system of the cockroach. J. Comp. Neurol. 207: $223-238$.

Bishop, C. A., M. O'Shea, and R. J. Miller (1981) Neuropeptide proctolin (H-Arg-Tyr-Leu-Pro-Thr-OH): Immunological detection and neuronal localization in insect central nervous system. Proc. Natl. Acad. Sci. U. S. A. 78: 5899-5902.

Bittner, G. D. (1977) Trophic interactions of crustacean neurons. In Identified Neurons and Behavior of Arthropods, G. Hoyle, ed., pp. 507-532, Plenum Press, New York.

Bradbury, A. G., and B. Mulloney (1982) Proctolin activates and octopamine inhibits swimmeret beating. Soc. Neurosci. Abstr. 8: 736

Brown, B. E. (1967) Neuromuscular transmitter substance in insect visceral muscle. Science. 155: 595-597.

Brown, B. E. (1975) Proctolin: A peptide transmitter candidate in insects. Life Sci. 17: 1241-1252.

Brown, B. E., and T. Nagai (1969) Insect visceral muscle: Neural relations of the proctodeal muscles of the cockroach. J. Insect Physiol. 15: 1767-1783.

Brown, B. E., and A. N. Starratt (1975) Isolation of proctolin, a myotrophic peptide from Periplaneta americana. J. Insect Physiol. 21: $1879-1881$.

Chan-Palay, V., A. G. Engel, J. -Y. Wu, and S. L. Palay (1982) Coexistence in human and primate neuromuscular junctions of enzymes synthesizing acetylcholine, catecholamine, taurine and $\gamma$ aminobutyric acid. Proc. Natl. Acad. Sci. U. S. A. 79: 7027-7030.

Clement, J. F., A. K. Taylor, and S. J. Velez (1983) Effects of a limited target area on regeneration of specific neuromuscular connections in the crayfish. J. Neurophysiol. 49: 216-226.

Evoy, W. H., and R. Beranek (1972) Pharmacological localization of excitatory and inhibitory synaptic regions in crayfish slow abdominal flexor muscle fibers. Comp. Gen. Pharmacol. 3: 178-186.

Evoy, W. H., D. Kennedy, and D. M. Wilson (1967) Discharge patterns of neurones supplying tonic abdominal flexor muscles in the crayfish. J. Exp. Biol. 46: 393-411.

Gillary, H. L., and D. Kennedy (1969) Neuromuscular effects of impulse pattern in a crustacean motoneuron. J. Ncurophysiol. 32: 607612.

Hoy, R. R., G. D. Bittner, and D. Kennedy (1967) Regeneration in crustacean motoneurons: Evidence for axonal fusion. Science 156: 251-252.

Kennedy, D., and K. Takeda (1965) Reflex control of abdominal flexor muscles in the crayfish. II. The tonic system. J. Exp. Biol. 43: 229246.

Kravitz, E. A., C. R. Slater, K. Takahashi, M. D. Bownds, and R. M. Grossfeld (1970) Excitatory transmission in invertebrates: Glutamate as a potential neuromuscular transmitter compound. In Excitatory Synaptic Mechanisms, P. Anderson and J. K. S. Jansen, eds. pp. 85-93, Universitetsforlaget, Oslo.

May, T. E., B. E. Brown, and A. N. Clements. (1979) Experimental studies upon a bundle of tonic fibers in the locust extensor tibialis muscle. J. Insect Physiol. 25: 169-181.

Miller, T. (1979) Nervous vs. neurohormonal control of insect heart beat. Am. Zool. 19: 77-86.

O'Shea, M., and M. E. Adams (1981) Pentapeptide (proctolin) associ- ated with an identified neuron. Science 213:567-569.

O'Shea, M., and C. A. Bishop (1982) Neuropeptide proctolin associated with an identified skeletal motoneuron. J. Neurosci. 2: 1242-1251.

O'Shea, M., J. Witten, and M. Schaffer (1984) Isolation and characterization of two myoactive neuropeptides: Further evidence of an invertebrate peptide family. J. Neurosci. 4: 521-529.

Page, C. H. (1982) Control of posture. In The Biology of Crustacea, D. C. Sandeman and H. L. Atwood, eds., Vol. 4, pp. 33-59, Academic Press, New York.

Penzlin, H., H. Agricola, M. Eckert, and T. Kusch (1981) Distribution of proctolin in the sixth abdominal ganglion of Periplaneta americana and the effect of proctolin on the ileum of mammals. Adv. Physiol. Sci. 22: 525-535.

Piek, T., and P. Mantel (1977) Myogenic contractions in locust muscle induced by proctolin and by wasp, Philanthus triangulum, venom. $\mathrm{J}$. Insect Physiol. 23: 321-326.

Pitman, R. M. (1975) The ionic dependence of action potentials induced by colchicine in an insect motoneurone cell body. J. Physiol. (Lond.) 247: 511-520.

Schwartz, T. L., R. M. Harris-Warrick, S. Glusman, and E. A. Kravitz (1980) A peptide action in a lobster neuromuscular preparation. J. Neurobiol. 11: 623-628.

Sokolove, P. G., and W. G. Tatton (1975) Analysis of postural motoneuron activity in the crayfish abdomen. II. Coordination by excitatory and inhibitory connections between motoneurons. J. Neurophysiol. 38: 332-346.

Sternberger, L. A. (1979) Immunocytochemistry, John Wiley \& Sons, Inc., New York.

Sullivan, R. E. (1979) A proctolin-like peptide in crab pericardial organs. J. Exp. Zool. 210: 543-552.

Sullivan, R. E., K. Tazaki, and M. W. Miller (1981) Effects of proctolin on the lobster cardiac ganglion. Soc. Neurosci. Abstr. 7: 253.

Sylvia, V. L., and G. M. Holman (1983) Isolation and high-performance liquid chromatographic purification of a myotropic peptide from the hindgut of the crayfish, Procambarus clarkii. J. Chromatogr. 261. 158-162.

Takeuchi, A., and N. Takeuchi (1964) The effect on crayfish muscle of iontophoretically applied glutamate. J. Physiol. (Lond.) 170: 296317.

Usherwood, P. N. R. (1980) Neuromuscular transmitter receptors of insect muscle. In Receptors for Neurotransmitters, Hormones and Pheromones in Insects, D. B. Sattelle, L. M. Hall, and J. G. Hildebrand, eds., pp. 141-152, Elsevier/North Holland Biomedical Press, New York.

van Harreveld, A. (1936) A physiological solution for freshwater crustaceans. Proc. Soc. Exp. Biol. Med. 34: 428-432.

Velez, S. J., and R. J. Wyman (1978a) Synaptic connectivity in a crayfish neuromuscular system. I. Gradient of innervation and synaptic strength. J. Neurophysiol. 41: 75-84.

Velez, S. J., and R. J. Wyman (1978b) Synaptic connectivity in a crayfish neuromuscular system. II. Nerve-muscle matching and nerve branching patterns. J. Neurophysiol. 41: 85-96.

Walker, R. J., V. A. James, C. J. Roberts, and G. A. Kerkut (1980) Neurotransmitter receptors in invertebrates. In Receptors for Neurotransmitters, Hormones and Pheromones in Insects, D. B. Sattelle, L. M. Hall, and J. G. Hildebrand, eds., pp. 41-57, Elsevier/North Holland Biomedical Press, New York.

Watson, W. H., III, G. J. Augustine, J. A. Benson, and R. E. Sullivan (1983) Proctolin and an endogenous proctolin-like peptide enhance the contractility of the Limulus heart. J. Exp. Biol. 103: 55-73.

Wine, J. J., J. E. Mittenthal, and D. Kennedy (1974) The structure of tonic flexor motoneurons in crayfish abdominal ganglia. J. Comp. Physiol. 93: 315-335. 